\title{
Abandoning Extensive Management: Meaning and Countermeasures of Delicacy Management for Study Style Construction in China's Colleges and Universities
}

\author{
Jun Wang \\ No.25, Zhujiang Road, Hexi District, Tianjin, China, 300222 \\ keldes@126.com.
}

Keywords: Chinese colleges and universities, Study style construction, Delicacy management.

\begin{abstract}
Study style construction has been regarded as the first priority of teaching and management task in the colleges and universities, but it is difficult for China's colleges to take extensive management to meet the needs of the times. To cultivate high-quality talents, restrain the study style issues caused by increasing enrollment of colleges, it is necessary to bring into the theory of delicacy management of enterprises, using its management ideas to restrain the behaviors of teachers and students, to ensure that high-quality study style will be rooted in the blood of every student.
\end{abstract}

\section{Method and Meaning of Implementing Delicacy Management in China's Colleges and Universities}

In facing such study style issues as paying more attention to scientific research than teaching, failure in seriously preparing for lessons, loose in exams, skipping classes, cheating in the exams, delicacy management provides a beneficial direction, that is, to practice the management responsibility, make every task more specific, clear and targeted, supervise each teacher and management staff to do better with scientific and reasonable system, procedure and standard. We should do regular examination on every task, and solve the problems as soon as possible. Therefore, it can ensure the benign development of study style, improve the teaching and learning, increase the teaching quality, providing security for cultivating high-quality talents.

Take serving teachers and students as orientation, and make serious delicacy management institutions

Administrative management staff must set up humanistic concept, implementing delicacy management is not for restraining teachers and students, but for improving education and teaching quality, changing the trend of decline in teaching and learning style, in order to set up a new lofty status of colleges and universities, and save the confidence in high education. Of course, advocating the delicacy management of study style construction should regulate the behaviors of many teachers and students, improve the management quality, and also be beneficial for giving full play to the subjective initiative, without restraining or limiting innovative ideas.

Implementing delicacy management, should abandon "human rule", lay down serious regulations of teaching, exams, attendance, and graduation thesis design, making management more legal and standardized. Ensuring the details and content in form of system, and giving full play to the importance of "everyone do business, and everything is in one's responsibility", to improve the system management process of colleges, and realize that laws to abide by, rules-based, no matter transition of leadership, replacement of teachers and students, to achieve the goals of qualitative leap of study style.

Encourage teachers and students to participate, vigorously promote the implementation of delicacy management

To better implement delicacy management system, we must advocate the enthusiasm of all the people, and make everyone know that each teacher and student are the object of delicacy 
management, and the person who carry out and participate in. Through everybody's participation, whole-process penetration, and all-round implementation, stimulate good practice, good experience of delicacy management. Teaching management staff should follow the mass line, listen to the advice and suggestion of teachers and students, timely correct the mistakes and out-dated management method, encourage management innovation, in order to realize the fruitful results for delicacy management research.

By generalization, we hold that in the process of delicacy management, there are 6 points: 1, make sure that all the teachers and students participate in and be self-disciplined; 2, advocate the tasks of all the departments be quantitative, specific, and clearly responsible; 3 , give play to the management function of all the colleges and departments, and improve the cooperative sense; 4 , the members of all the leadership should make practical investigation and research at the grass-roots level, and guide to work; 5, solve the problems timely and increase working efficiency; 6, open the communication channel of cadres and the masses, pursuing humanistic management.

\section{Strengthen the work of publicity guidance, and perfect delicacy management plans}

It is noticed that at the early period of delicacy management implementation, because of emphasis on management details, being contrary to loose management environment at past, it may cause the mental inadaptation of teachers and students, even resisting mood. Therefore, in the implementation process, we should deal with the relationship between the whole and the part, group and individual, grasp the details, improve the psychological counseling and explain the related policies, strengthening the communication and coordination between managers and person to be served, making delicacy management shifting from passive management to voluntarily accepting the management, and then gradually turns to a voluntary behavior of each teacher and student, then promote the overall development of school, teaching and study style.

Delicacy management task should be included into the index of year-end assessment, and for the teachers and staff who fail to carry out or are not effective, we should make it public in the school, and the year-end assessment cannot be excellent, or other measures that delay one year for the title of technical post promotion. Office of teaching affairs should regularly holds symposium of delicacy management, knowing the feelings of teachers, students and parents to the task and the effect of the current way, drawing its lessons, and looking for the problems and defects, to improve delicacy management plan and measures of implementation, optimizing the implementation process.

\section{Straighten out the relationship and clarify the responsibility, present the fair and just spirit of delicacy management}

The delicacy management proposes more demands to teachers, students and administrative staff, and strictly elaborate the task goals, with the increase in workload, it must cause the dissatisfaction of all the people. However, we must ensure that it is good to the university, to the students and to the education undertaking, no matter the difficulties, we must firmly carry it out, changes may naturally influence some person's interests, but it can make higher education more vital and educate more high-quality talents.

For delicacy management, we must emphasize that: fairness, that is, delicacy management system treat everyone equally. For the system about teachers, all the teachers must abide by, include the president; for the system about students, all the students must abide by, without discrimination of study result and family condition. Once violating the regulations, we must strictly deal with it. In fact, delicacy management is to use "system management" to replace "human management", if it is fair and just, can it be trusted by all the teacher and students, it will be an effective security for the success of delicacy management.

Moreover, delicacy management does not mean more is better, system does not exactly mean the delicacy of management, more disorderly system will damage management order, whether the system is scientific and reasonable is the key to decide the level of delicacy management. Of course, making delicacy management system is to improve the teaching and study style of the school, to 
enforce the delicacy and standard of teaching affairs management, but if the system cannot be implemented, delicacy management will be formalism, and have no positive effects. Therefore, it is necessary to establish and improve the supervision and reflection mechanism, meanwhile, advocate and stimulate the teachers and students' initiative by encouragement mechanism, in order to further promote the overall, coordinated and sustainable development of delicacy management.

To sum up, through the delicacy management, we can require the students in each stage of learning process with standards, such as listening lessons, taking note, discussing, reading after class, taking exams, and doing social practice, caring about everyday and every lesson of the students, setting up the growth record. Meanwhile, it can also better supervise teachers' preparing for lesson, teaching style, homework examination, practice guidance, and fully stimulate the enthusiasm in the form of quantitative assessment.

\section{Measures and suggestion of delicacy management in China's universities and college}

Currently, the study style construction of many universities and colleges in China still has general and obscure management demand, in long term, it is harmful for the development of school spirit and study style, therefore, we must implement the standardized management, streamline operations and delicacy implementation of study style construction, making related regulations specific, clarify everyone's responsibility, set up the rules of sequence, steps and demands, to effectively avoid disorder and inefficiency. Our goal is to bring management into every process, link and step, making work regular and orderly, inspection standardized, reward and punishment accordingly, to form a working atmosphere that everyone wants to work, can do work and do it effectively. Meanwhile, we must realize humanistic management, continuously innovate service content, forms and ways, promote professional level and quality, trying to build the brand of study style construction.

\section{Measures and suggestion of delicacy management of teaching atmosphere}

We should practically give full play to the model function of teachers. Teachers of upright attitude have a positive effect on the forming of good study style. If a teacher is not serious in preparing lessons and teaching, how can he demand the students to seriously listen the lesson and take note and do homeworks? We must encourage to prepare for lessons in form of groups, making teaching video, through delicacy management theory, we can regulate the good methods, and set specific work demand and evaluation standard of reward and punishments, strengthen the ability of teacher's team from the source and promote learning by teaching.

As for the problems of senior teacher's slack in teaching, and young teacher's lacking in responsibility, we hold there are measures to solve: taking 3 years to be a cycle, every department's teachers are divided into 3 batches, and organize expert team to audit teaching with a group of teachers, the expert team is composed by outside experts, experts of the school and those of the major, the group should be flexible, limit the proportion of experts of the college and department, if the condition is allowed more expert teams is the best choice. By scoring, generalize the effect of class teaching to be excellent, good, ordinary and poor. For teachers who are evaluated to be excellent, teaching performance salary is paid according to $120 \%$ as a reward; for those who are good, the teaching performance salary is paid according to $80 \%$; if unfortunately evaluated to be poor, not only the performance salary is paid according to $50 \%$, but also the weekly amount of lessons is limited. After one year of rectification, the teachers who are evaluated to be ordinary and poor are allowed to submit application for a new discussion, if conforming to the demand, can increase the discussion for him. With such kind of reward and punishment, the total paying amount of teaching performance salary cannot be largely different, and the initiative of all the teachers can be stimulated, teachers who has poorer teaching effect also can make progress due to personal interest, the teaching atmosphere must be changed better a few years later.

\section{Measures and suggestion of delicacy management of examination atmosphere}

Exam discipline is an important content of study style construction, with the large decrease in 
student's quality and that teacher pay less attention to the term-end exams, the exam discipline is sluggish, personal cheating turns to group's cheating, academically poor student's cheating turns to good students cheating for scholarship, chance of postgraduate recommendation. If the bad behavior cannot be timely stopped, it will influence the newly attending students, harming the school and study atmosphere. In view of this, we should carry out the following aspects. First, to increase the effort of reward and punishment, we may set high scholarship and increase the chance to postgraduate recommendation for good students, to stimulate students to supervise each other for the benefit, and cancel the result if the student is cheating, and with criticizing and warning punishment; second, to treat exam discipline as strictly as CET4 and CET6, cell phone and other related goods are not allowed before entering in the exam classroom, once finding the cheating behavior, supervising teachers should sign names and make sure of it, otherwise, if the student refuse to sign name, teachers will be passive, the students who do not want to cheat will take the chance. Third, to allow the students to apply for delaying taking exams and credit interchange, because there are a few exams in a week, it is difficult for study disadvantaged students to make a review, he or she may take cheating, so we should make more humanistic exam plans, even delaying graduation; fourth, to enforce the cultivation of study atmosphere of all the classes, establish study groups according to dorms, interests, preparing for postgraduate exams, and studying abroad, let the best student lead the students to do self-study as the leader, and improve the formation of study atmosphere. Moreover, as for the problems of shortage in self-study rooms reflected by the students, although it has not happened any accidents, the teaching affair department should write classroom's using situation of all the periods, and make it public and renew it everyday( present the self-study classrooms with electric guiding plate at the gate of every teaching building),meet the needs of students as far as possible.

Teaching affair department can make detailed implementation measures and reward and punishment standard and seriously conform to it, to achieve the goal with long-term and delicacy management. Some may think that hard system measures can not continue due to refusal, in fact, as long as the measures is proper, implementation is fair and just, it will be popular.

\section{Improve reward and punishment mechanism, promote the advantaged by reward, and encourage the disadvantaged by punishment}

To promote the delicacy management of study style construction, the primary goal is to strengthen the responsibility of all the teachers and staff, letting everyone to love and depend on the school. We must do the mechanism construction, realize delicate, regular and humanistic management by optimizing management mechanism, improving encouragement mechanism, perfecting democracy mechanism, gradually increase the enthusiasm for delicacy management of all the teachers and staff. Through assessment and conclusion, actively spread the excellent experiences, summarize unsatisfactory parts, look for the reasons and make improvement. In view of it, we propose the following suggestions:

On one hand, we should promote the internalization of delicacy management through encouragement and evaluation. We hold that in the process of delicacy management, must take human development as the core of education tasks, no matter teachers or students, all have mental needs, as long as the needs is respected, can the person be managed voluntarily accept the institution's restriction and regulations. Under the condition of specific demand on management and increase in responsibility, management in the past can always cause the resisting mood of the managed, leading to bad effect. Therefore, we must care about every teacher and student, supervise them to finish study and works efficiently by management mechanism, enforce their responsibility sense by careful working style, and stimulate working enthusiasm by evaluation of encouragement and rewards, in order to achieve the goals of each part, lay a favorable foundation for the formation of high-quality study style.

On the other hand, we should promote the internalization of delicacy management through construction of campus culture. Delicacy management originates from sense of high-quality goods, which emerges from excellent campus culture. In fact, delicacy management is a kind of cultural self-discipline, needs improvement of all kinds of regulations and guidance of campus culture. We must take cultivation of featuring culture to be forceful way to promote favorable development of school atmosphere, teaching and study style, through active guidance from top to bottom and 
voluntary response from bottom to top, make sure the management thought of delicacy management led by cultural construction, actively promote the cultural tradition and management level of school, continuously increase teachers and students' sense of identity. Meanwhile, the cultural inheritance of theory on school management and school spirit and motto, is beneficial for the teachers and students to develop and realize the goals of inspiring and encouraging person by featuring culture. Therefore, all the teachers and students will form a favorable atmosphere that teachers and students are proud of school and devote to it, to achieve delicacy management's role in promoting school development and individual growth.

To sum up, in the process of delicacy management, we must follow the service principle of human-oriented, manage people by institution and do things according to it, optimize encouragement and reward mechanism, form an evaluation system "low starting point, small goal, diligent evaluation, fast response", to stimulate working and study driving force. We should keep innovating the development of high-quality campus culture, rectify school atmosphere, promote teaching style, and influence study style, shaping noble teaching spirit, and cultivating talents, forming positive energy of higher education. According to the principle of "full of love, strict supervision, careful examination", improve the internalization of delicacy management, relieve the pressure of teachers and students, making everyone work and study under the condition of sunshine service, evaluation and mood.

\section{Conclusion}

Delicacy management is a kind of concept, and also a kind of culture, it is a kind of management pattern which is characterized by "accurate, careful, deep and regular", to be accurate is the key of management, to be careful is the quantitativeness, examination, supervision and implementation of management standard. The core of delicacy management is to carry out rigid system, to regulate human behavior, to strengthen the implementation of responsibility, and to form a good implementation culture.

Therefore, to implement delicacy management is mainly for increasing working implementing force, avoid the negative influence of bad study style, rather than restricting the function of management apartments, and limiting the freedom of teachers and students, otherwise, the management departments and teachers and students will be tired, cannot achieve the goal of improving school development. As long as the teachers and students make sense that following delicacy management system can not only be beneficial for school construction, but also can improve the undertaking's development and study progress of teachers and students, it can create a favorable atmosphere in which teachers and students will consciously abide by and implement the institution instead of passively accepting institutional management.

\section{Acknowledgement}

About the author, Wang Jun, got his master degree from Nankai University. He is the chief director and assistant researcher of the Polytechnic Institute in Tianjin University of Finance and Economics. His research field includes higher education management.

\section{References}

[1] Jiang Xiuying, Delicacy management on Teaching and Management, Contemporary Education Sciences 2011(11):63-64.

[2] Yang Guoqing, Theory and Practice of the New Model of School Ethics Construction, Research on Higher Education 2011(4):21-23.

[3] Zhang Qin, On the Fine-Grained Teaching Management in High Education, Theory and Practice of Contemporary Education 2010(5):92-93.

[4] Li Qiang, Sun He. On the Four Aspects of the Theory on Fine-Grained Teaching Management in High Education, China Higher Education 2010(1):30-31. 